\title{
Topocorpografias - o ensino de dança na comunidade escolar do bairro João Paulo
}

Felipe Ferreira Ferro

Recebido em 10/03/2018

Aprovado em 08/10/2018 
Este texto é um relato acerca de experiências que emergiram do ensino de dança na Escola Básica Municipal José do Valle Pereira, situada na cidade de Florianópolis. As aulas foram ministradas no contexto da disciplina Estágio na Comunidade II (UDESC) e estiveram apoiadas por Proposições para uma Pedagogia Radical, ou Como Repensar Valores, texto elaborado por Erin Manning. Nestes termos, o trabalho procurou elaborar propostas de ensino de dança na perspectiva da arte relacional, considerando a comunidade escolar como campo potente para o estudo da dança e das repercussões das aulas no cotidiano extraescolar das crianças e adolescentes.

Palavras-chave: Dança. Arte do Corpo Relacional.

Comunidade Escolar. Artisticidade.

\section{INTRODUÇÃO}

Qual a duração de um encontro? Início meu relato com esta pergunta sem no entanto pretender respondê-la com exatidão. Tal questionamento é como uma luz que pisca sempre quando me deparo com a sensação de que algo importante e incomensurável aconteceu. Portanto, é a partir de um destes eventos que começo a narrativa das memórias que compõem a experiência do estágio.

Aconteceu na tarde de um domingo. Estávamos, eu e meus colegas, dançando na Ponta do Coral quando em meio a algum improviso baseado nos princípios da dança contato impulsos, intercâmbio de pesos, rolamentos, dança que surge do toque entre corpos - escuto alguém me chamando:

\section{-Professoooor Professoooor!}

Sem interromper a dança olho ao redor, vasculhando o espaço para confirmar o que eu havia escutado. "Quem me chama?", pensei. Ela estava ali, agarrada à rede de proteção do brinquedo Pula-Pula. Laura, uma criança de uns 10 anos me olhava com atenção. Fiquei feliz por reencontrá-la. A jovem Laura havia participado das aulas de dança conduzidas por 
mim na Escola Básica Municipal José do Valle Pereira e, deste modo, tive aa sensação de que ali, naquele domingo, teríamos a oportunidade de dançar mais uma vez, agora fora da escola. Laura nos olhou com curiosidade e um pouco de timidez. Passava sempre ao largo da pista de dança com os olhos atentos. Numa destas passagens resolvi convidá-la sem usar qualquer palavra, somente com a ação de aproximar-me dançando, algo muito parecido com o que já havíamos vivenciado nas aulas. A menina percebeu minha aproximação e eu percebi que ela percebeu. $\mathrm{E}$ assim sentimos a tensão provocada pela decisão a ser tomada: entrar ou não nesta dança? Eu sentia que algo a impulsionava a dizer sim e outro algo, talvez a indecisão ou a timidez ou talvez a dúvida de lançar-se ao que não sei nominar agora, a segurava. No entanto, Laura escolheu dançar! Dançamos por alguns minutos, primeiro eu e ela, depois outros colegas aproximaramse dançando também. Estávamos dançando a dança contato, ou contato improvisação, como queiram chamar.

A menina sempre atenta e disponível apresentou-me sutilmente a força relacional do que estávamos fazendo ali e do que havíamos realizado na escola. Tive este insight dançando com ela, naquele lugar, com todas aquelas pessoas, debaixo daquela árvore, com aquele sol e mar daquele dia. Foi um pensamento que me aconteceu dançando naquele momento. Poderíamos pensar, portanto, que o evento principal deste relato é a dança criada por Laura, eu e meus companheiros. Contudo, alargando o campo perceptivo desta experiência quero recuperar em nossas memórias o olhar e a disponibilidade de Laura para relacionar-se com o imprevisto que lhe fora ofertado: Pessoas desconhecidas e outras quase-desconhecidas dançando debaixo de uma árvore num dia de domingo. Citando o filósofo Brian Massumi ${ }^{1}$ (2017), podemos dizer que nascemos numa "exuberância" hiperconectiva funcional. Ou seja, somos um lago de sensações que estão em profusa conexão, porém,

' Filósofo e teórico social canadense. A pesquisa de Massumi abrange os campos da arte, arquitetura, estudos culturais, teoria política e filosofia. Seu trabalho explora a interseção entre poder, percepção e criatividade para desenvolver uma abordagem de pensamento e ação social que une os domínios estético e político. Ele é professor aposentado do Departamento de Comunicações da Université de Montréal.Narrativa como descrição do que vimos nos relatos produzidos durante o FGB. 
elas não se apresentam em uma composição sucessiva e hierárquica, mas em gradações na intensidade de sua presença criando uma co-composição de sensações; Por exemplo, imagine um bebê: ele ouve com a boca, escuta com a pele e ossos enquanto sente o gosto das árvores. Quantas outras percepções podem estar intensificadas naquele corpo pequeno? O que Massumi (2017) nos diz é que ao nascermos estes poucos sentidos convencionalmente nomeados como tato, paladar, audição, visão e olfato são só alguns poucos sentidos dentre inúmeras outras possibilidades de urdidura. O bebê, no auge da hiperconectividade sensorial percebe a vida num emaranhado de sentidos: a vida pulsa naquele corpo com muita intensidade. Porém, Massumi (2017) nos tranquiliza ao dizer que nós adultos não perdemos a capacidade de sentir muito, e que nem tudo está perdido. Segundo o autor, nós apenas estamos intensificando alguns poucos sentidos devido ao contexto normativo ao qual acreditamos fazer parte completamente, e que ainda assim, nosso olfato só se sustenta por estar em associação a outros sentidos num movimento infinto de mudanças em sua intensidade e que, é muito importante destacar isso, nossos sentidos não estão encerrados em si e que nossos corpos estão em constante comunicação através do espelho tátil (ou dos neurônios-espelho). Estamos, portanto o tempo todo em estado de composição (o que ele denomina de "uma geologia da experiência") e, tal qual é pensado por ele, "se a percepção é uma composição, há uma AR-TIS-TI-CI-DA-DE inerente a ela" (p.10). Para o filósofo, neste sentido,

enquanto essa artisticidade da experiência não é de nenhum modo limitada ao domínio institucional da arte, expandir-la é algo que a arte pode fazer, quando faz jus ao seu nome. Ela faz jus ao seu nome quando trás novas variações intensivas no relevo - ao assumir sua missão: variar as intensidades "geológicas" que dão forma às experiências (ao invés de combinar formas pré-determinadas) (MASSUMI, 2017, p. 11).

A vida é grande, flui e se intensifica fora dos códigos e normas criados para nos fazer acreditar que a vida é estática e que está tudo sob controle. Partindo desta premissa emprego a "arte do corpo relacional" (2017), conceito apresentado 
pelo filósofo canedense no referido texto, como proposição pedagógica de especulação criativa através da dança: o encontro de corpos numa comunidade é primordialmente sinestética e, deste modo, criador de "uma geologia da experiência" (p.10). Por este caminho e reiterando o termo apresentado anteriormente, a prática de ensino da dança parte de uma artistidade inerente à composição dos sentidos dos inúmeros corpos presentes na experiência do encontro. Veja só o que o encontro com Laura nos proporcionou. João Guimarães Rosa, escritor mineiro, escreveu algo muito próximo desta compreensão acerca da infinitude de intensidades: mire e veja: o mais importante e bonito, do mundo é isto: que as pessoas não estão sempre iguais, ainda não foram terminadas - mas que elas vão sempre mudando. Afinam e desafinam. (p. 39).

Particularmente, acho que as discussões conceituais são muitas vezes complexas e difíceis. Por este motivo, o estágio na comunidade tem sido importante para que eu possa retomar minhas experiências com outra escuta sobre o processo. Por isso encontrar Laura na Ponta do Coral ${ }^{2}$ me fez olhar para a paisagem das aulas de outro modo, pois ali naquele encontro estavam presentes inevitavelmente todas estas qualidades perceptivas e conceituais pelas quais temos navegado no Lab.E.I ${ }^{3}$ e nas orientações de estágio: A intuição, o inefável, o espaço entre das relações, a escuta, a criação como procedimento pedagógico.

Naquela dança com a criança compreendi um pouco mais que meu papel como condutor do processo de dança está ligado a criação de campos onde a experiência é o lugar da criação que é ao mesmo tempo pedagogia da dança, ou

\footnotetext{
2 Ponta do Coral é uma área pública situada à beira-mar onde o Movimento Ponta do Coral (Parque Cultural das Três Pontas) atua em defesa do parque cultural frente ao avanço da especulação imobiliária que incide sobre o local.Narrativa como descrição do que vimos nos relatos produzidos durante o FGB.

${ }^{3} \mathrm{~A}$ partir da continuidade do interesse no que se partilha mas não se vê (o intangívelsensível), o Labei investiga a ideia de Espaços de Aterrisagem como lugares de atenção, (não localizações sitiadas). Onde está a atenção constrói-se ilhas de presença. Ilhas são mundificações emergentes, formadas na confluência de tudo o que está partido do todo, nesse tecido disjuntivo que chamamos espaços públicos. O laboratório busca partir e transduzir o comum, a partir de improvisações, proposições sitiadas, condições permissivas que invocam uma sintonia de afetos.
} 
da arte. Neste sentido, dialogo com o texto "A Dança Criativa e o Mito da Criança Feliz" escrito por Isabel A. Marques ${ }^{4}$. Citando-o rapidament para pontuar o aspecto pedagógico da arte citado acima, destaco o tensionamento que a autora produz ao criticar as práticas de ensino da dança nas escolas brasileiras. Segundo Marques (1997), o conceito "dança educativa" (1997, p. 30) implica na separação da dança em duas possibilidades: a dança destinada às crianças da escola e a dança feita por artistas. De tal modo, de acordo com a questão apresentada por Marques (1997, p.30), a criação em dança não seria por si o espaço pedagógico da arte, seja este na escola ou num grupo profissional? O processo que impulsionamos neste estágio é uma pesquisa-criação em artes da experiência, da relação, do movimento e da dança, ou pelo menos é uma tentativa de que assim seja. E mais, além do ensino de códigos de diversas danças não seria mais uma vez este o lugar de criarmos e vivermos outras possibilidades de relação com a vida em termos espaciais e relacionais? $\mathrm{E}$ desta relação, não estaríamos criando novos mundos?

As aulas aconteceram na Escola B.M José do Valle Pereira, no bairro João Paulo, lugar onde muitas famílias de pescadores habitam. As crianças e adolescentes que frequentaram as aulas são parte desta comunidade e os encontros aconteciam no contra-turno das aulas regulares, por este motivo, configuraram-se como atividades do estágio na comunidade, ainda que estivessemos na escola.

A seguir apresento algumas experiências vividas por nós na escola como forma de delinear um pouco da "geologia da experiência" criada nos encontros semanais.

${ }^{4}$ Professora na Faculdade de Educação da UNICAMP. Representa no Brasil a dance and the Child International (daCi), UNESCO. 


\section{A DISPERSÃO DA TERRA}

Desenvolvemos uma experiência com garrafas cheias de terra. Cada criança trouxe a sua. O primeiro imprevisto apareceu quando elas me levaram a uma parte da escola em que eu ainda não havia estado. Este outro lugar me foi apresentado por uma motivação: precisávamos manter a sala limpa. Deste modo, fui conduzido por cinco crianças a um grande espaço: piso de terra, parquinho e horta compunham aquele lugar. Levando comigo uma caixa de som, coloquei imediatamente a música que havia separado para este momento. A proposição inicial era apenas espalhar aquela terra pelo "quintal da escola", porém, as crianças criaram ali intuitivamente uma coreografia que consistia na dispersão da terra em torno de si a partir de movimentos circulares com as garrafas sem tampa em mãos. O grande quintal, a terra, as garrafas, a música, a agradável manhã de sol e o deslocamento imprevisto para este espaço nos colocaram diante de uma experiência ímpar. Nós seis sabíamos que algo diferente estava acontecendo ali. Esta experiência nos permite dialogar com a abertura ao "mais-que", conceito proposto por Erin Manning5 no livro The Minor Gesture (2017). Ao pensar sobre o que é importante numa técnica, Manning diz que "dance technique involves the honing of repetitive movements, but it also encourages the experimentation of what else those movements can do" (2017, p. 40). Este "mais-que" que emerge da repetição de uma técnica é da ordem do inefável e a sua transcrição, ainda que dificultosa, pode ser feita através de registros do processo, como neste caso onde crio o relato sobre a coreografia imprevista criada pelas crianças. Algo a mais reorientou a proposição performativa com as garrafas abrindo espaço para a coreografia no pátio externo da escola.

\footnotetext{
${ }^{5}$ Teórica cultural canadense e filósofa política, bem como um artista praticante nas áreas de dança, design de tecidos e instalação interativa. A pesquisa de Manning abrange os campos da arte, teoria política e filosofia. Ela recebeu seu doutorado em Filosofia Política pela Universidade do Havaí em 2000. Atualmente leciona na Faculdade de Belas Artes da Universidade de Concordia (Montreal - Canadá).
} 


\section{DETERMINISMO DOS PASSOS COREOGRAFADOS}

Desde o princípio do processo havia a expectativa de que eu fosse lhes ensinar passos de dança conhecidos. Como a proposta que trouxemos para este estágio era outra e um tanto estranha às referências deles de dança, houve certa dúvida sobre a aula ser ou não ser sobre dançar. Não faço aqui crítica à noção de coreografia que se vincula aos conceitos mais tradicionais de dança, aqueles que se pautam em técnicas e desenhos já conhecidos, afinal, também podem criar a partir dessas. O que me chamou atenção foi a resistência em experimentarmos outros códigos de dança, tão ou mais complexos que (aqueles) conhecidos por elas. Por exemplo, a coreografia da Pablo Vittar era bem vinda e movia muitos deles à dança, no entanto, a proposição experimentarmos a mesma coreografia com outra música causou estranhamento. "O que é a dança?", então, nos perguntamos. A dança está na coreografia? A dança está na música? Está na coreografia e música juntas? Quando estou dançando? Esta foi uma pergunta que ficou sem respostas, no entanto, no último dia, por sugestão das crianças, a mesma coreografia foi dançada ao som de outra música.

\section{O COMPORTAMENTO RUIM - O QUE MOTIVA A DANÇA?}

No mesmo dia, a aluna Flor, frequentemente apontada como criança sem desordeira, realizou uma dança improvisada. Eu e ela dançamos enquanto o professor Ricardo Levy tocava bateria. Sem acordo prévio, movidos pela relação com o espaço e com a bateria, dançamos por algum tempo muito concentrados criando no aqui e agora pequenas estruturas coreográficas que apareciam dos movimentos que realizamos enquanto nos relacionávamos dançando. Flor, a criança mais desordeira e tensionadora das normas da escola, criou uma dança coreografada na relação e conectada com a paisagem sonora da sala. Ao mesmo tempo, os códigos que havíamos investigado nas aulas anteriores também estavam presentes: criamos 
situações de impulso na parede, de contato e apoio entre dois corpos dançantes, o olhar estava presente e também dançava. Dada tais considerações, podemos dialogar mais uma vez com Manning (2017) a partir da concepção de que a aprendizagem caminha em camadas sutis que estão além das hierarquias da instituição. Estas hierarquias tendem a priorizar determinados contéudos e formas, pautando o que é e o que não é válido no contexto escolar, acadêmico etc. Flor nos ensina muito a partir de sua negação a ordem da escola e nos apresentando em sua dança questões que não podem ser respondidas no campo da razão. A dança de Flor é o emaranhado de muitas perguntas que parecem emergir intuitivamente da relação. Manning (2017) no livro The Minor Gesture, diz:

As subcomissões abre o caminho para a elaboração de problemas maiores do que suas soluções. Aqui estou seguindo Henri Bergson, que sugere que o melhor problema é aquele que abre um processo intuitivo, e não aquele que já carrega dentro de si a sua correção. Um problema resolvido nunca foi realmente um problema, Bergson nos lembra. Somente quando uma questão está em linha com a criação de um problema é verdadeiramente operacional. (MANNING, 2017, p.10).

Nesta tensão entre a ordem e a desordem outro pensamento me apareceu: a importância da escuta. Tive que lidar com a realidade da experiência que é maior que qualquer planejamento feito anteriormente, ainda que este seja fundamental para a criação de condições que permitam que a experiência da relação seja emergente. A aula, deste modo, vai sendo criada de acordo com as condições do clima, dos espaços da escola, do estado emocional de cada criança e adolescente e do professor. Foi importante notar que, em diversos momentos, os próprios alunos criavam alguma movimentação conjunta que possibilitava a construção de um campo relacional. A tendência do professor seria interromper o que eles haviam começado em prol do planejamento feito por ele antes da aula. Este seria o desejo de garantir a aprendizagem dos alunos de acordo com aquilo que o professor e a instituição acreditam ser importante para a turma. Porém, entre uma proposição aceita e outras rejeitadas há sempre muitas coisas 
acontecendo e que fazem parte daquele processo. Para estar atento a estas relações emergentes é importantíssima a atitude de escuta e, às vezes, também é importante o silêncio. Silenciar e escutar para embarcar na experiência. Fui tomado por esta sensação após inúmeras tentativas de delimitar o caminho do processo e a leitura de Manning (2016) foi fundamental para a compreensão da força desta escuta paciente. Quanto a isto, em seu texto Proposições para uma Pedagogia Radical, ou Como Repensar Valores, ela diz:

Aprenda a ouvir desde o meio de tantas conversações. Conecte-se ao ritmo. Pense nelas como se fossem paisagem sonora....A paisagem sonora da aprendizagem está cheia de manchas de tinta que se alojam nos limites do que chamamos percepção. Pense no local da aprendizagem e delineie o que não pode exatamente ser articulado, ouça o que eles evocam, como soam, mesmo quando você quase não pode ouviIo (MANNING, 2016, p. 23).

Vale destacar que Proposições para uma Pedagogia Radical, ou Como Repensar Valores foi publicado na Revista Nupeart, volume 16 do ano de 2016. Originalmente publicada em INFLeXions: A Journal for Research-Creation, o texto de Erin Manning elenca algumas questões que dão suporte à práticas de pesquisa-criação, contextualizando as pedagogias radicais num campo deslocado das premissas do ensino tradicional, recorrendo enfim à abertura a imprevisibilidades e ao pensamento criado na experiência eminentemente especulativa.

Topocorpografias junciona, portanto, a topografia (desenho minuscioso da paisagem de um terreno, região etc) ao corpo para conceber a prática pedagógica como pensamento situado nas infinitas paisagens do corpo sinestético presentes na comunidade escolar. Este ponto de vista que privilegia as sutilezas criadas na aproximação entre espaço, corpo e dança posiciona o presente estudo no campo da pesquisa-criação onde o processo é ponto de ancoragem para as pedagogias radicais. Tocorpografias, pois, a paisagem dos sentidos criaram relevos impermanentes que convidaram alunos e professor a percorrê-los numa prática que buscava especular constantemente procedimentos de aprendizagem, como no 
caso deste projeto, onde a dança era a plataforma para a criação de proposições coreográficas. Estas coreografias, por sua vez, criadas ora por repetições de alguma coreografia existente ora na experimentação de técnicas de dança, de protocolos performativos em conjunto com deslocamentos permitidos pelo edificio escolar nos proporcionou resituar a prática pedagógica do ensino de dança na comunidade de modo a viabilizar e acolher imprevistos durante o processo. O improviso com Flor, a coreografia das garrafas com terra e o encontro com Laura são algumas memórias do processo e atuam aqui como relato de parte da experiência ou, finalmente, como arquivo de imprevistos que estiveram presentes nas aulas de dança. Estas situações, por sua vez, compuseram uma parte da geologia de acontecimentos que emergiram do estudo da dança na escola. 


\section{REFERÊNCIAS}

AGAMBEN, Giorgio. O que é o contemporâneo?. Chapecó: Argos, 2009.

BORGES, Jorge Luis. O Aleph. $3^{a}$ edição. São Paulo: Companhia das Letras, 2010.

DESGRANGES, Flávio. A formação de espectadores: relato de uma experiência in: O Ato do espectador - Perspectivas artísticas e pedagógicas. São Paulo: Hucitec Editora, 2017.

DESGRANGES, Flávio. A interferência dos processos de criação nos modos de recepção artística: percursos de um pretérito imperfeito in: O Ato do espectador - Perspectivas artísticas e pedagógicas. São Paulo: Hucitec Editora, 2017.

FREIRE, Ida Mara. Dança-Educação: O Corpo e o movimento no espaço do conhecimento. Cadernos Cedes, Florianópolis - SC, n.53, p. 31-45, abril, 2011.

GIL, José. Movimento Total - O corpo e a dança. Lisboa: Relógio D'Água, 2001.

LISPECTOR. Clarice. A Paixão Segundo G.H. Rio de Janeiro: RocCo, 1998.

MANNING, Erin. The Minor Gesture, Durhan: Duke University Press. 2016.

MANNING, Erin. Proposições para uma Pedagogia Radical, ou Como Repensar Valores (Tradução Bianca Scliar Mancini). Nupeart Revista, Vol. 16, 2016, p. 11-21. Original http:// www.inflexions.org/radicalpedagogy/main.html\#Manning

MARQUES, Isabel A. A dança criativa e o mito da criança feliz. R. min. Educ. Física, Visçosa, 5 (1), 1997, p. 28 - 39.

MASSUMI, Brian. A arte do corpo relacional: do espelhotátil ao corpo virtual. São Paulo: Galaxia, n.31, p. 05-21, abr. 2016. http://dx.doi.org/10.1590/1982-25542016126462

ROSA, João Guimarães. Grande sertão: veredas. Rio de Janeiro: Editora Nova Fronteira, 1985. 